\title{
Beryllium-7 production from oxygen by atmospheric cosmic rays
}

\author{
Yuji Nakamura, Hisao Mabuchi and Hiroshi Hamaguchi \\ Department of Chemistry, Faculty of Science, \\ University of Tokyo, Tokyo 113, Japan
}

(Received April 26, 1972; in revised form June 1, 1972)

\begin{abstract}
The production rates of ${ }^{7} \mathrm{Be}$ from ${ }^{16} \mathrm{O}$ by cosmic rays were measured at three locations of different latitudes and altitudes. From the altitude dependence of the production rates, the attenuation length of $L=165 \pm 30 \mathrm{~g} / \mathrm{cm}^{2}$ was obtained. This value falls in the range of the reported values obtained by physical methods for the atmospheric neutrons.

The experimental value at the sea level of the geomagnetic latitude, $\lambda=25^{\circ} \mathrm{N}$, was in good agreement with the value calculated from the generally accepted atmospheric neutron spectrum and the best estimated excitation function. The latitude effect on the production rate is also discussed.
\end{abstract}

\section{INTRODUCTION}

Since the experiment by LAL et al. (1960), several measurements of the radionuclides produced in laboratory chemicals by the atmospheric cosmic rays have been reported for various combinations of targets and nuclear reactions. (LAL et al., 1960; Rama and Honda, 1961a; Husain and Kuroda, 1968; TAKagi and TANAKA, 1969; BHANDARI et al., 1969; MABUCHI et al., 1971)

MABUCHI et al. (1971) reported the ${ }^{32} \mathrm{P}$ production from sulfur, and noted that the production rate at $\lambda=25^{\circ} \mathrm{N}$ is much lower than that observed at $\lambda=44^{\circ} \mathrm{N}$ by RAMA and HONDA (1961a), even if the difference of the latitudes is taken into account. In order to confirm this discrepancy, we have chosen another nuclear reaction, that is, production of ${ }^{7} \mathrm{Be}$ from oxygen. This reaction has a higher threshold value than the ( $n, p)$ reaction and was once investigated at $\lambda=51^{\circ} \mathrm{N}$ by LAL et al. (1960). Further experiment at different latitudes and altitudes will serve to confirm their result. The ${ }^{7} \mathrm{Be}$ production is important in connection with the production rate of ${ }^{10} \mathrm{Be}$ in the atmosphere.

In this paper we report the result of the experiment carried out at three locations; Tokyo (sea level, $\lambda=25^{\circ} \mathrm{N}, 1970$ ), Mt. Fuji ( $2345 \mathrm{~m}$ above sea level, $\lambda=25.5^{\circ} \mathrm{N}, 1970$ ), and Gif-sur-Yvette (sea level, $\lambda=50^{\circ} \mathrm{N}, 1971$ ) in France. 


\section{EXPERIMENTAL}

Target exposure and chemical procedure: Tap water was purified by a cationexchange resin. $\mathrm{Be}^{2+}$ carrier was added and the final $\mathrm{pH}$ was adjusted to $\sim 2$ with $\mathrm{HNO}_{3}$. The water target thus prepared was put into a number of polyethylene bottles $(30 \mathrm{~cm} \times 30 \mathrm{~cm} \times 25 \mathrm{~cm})$ and exposed to atmospheric cosmic rays.

After the exposure, beryllium was separated from a large quantity of water by a cation-exchange resin column (Diaion SK-1 A, 50-100mesh, $10 \mathrm{~cm} \phi \times 45 \mathrm{~cm}$ ). Beryllium was eluted by $4 \mathrm{~N} \mathrm{HCl}$ and then purified by precipitation of the hydroxide in the presence of EDTA. Finally, the hydroxide was ignited into $\mathrm{BeO}$ which was subjected to the measurement of radioactivity.

Counting of beryllium-7: The $477 \mathrm{keV} \gamma$-ray of ${ }^{7} \mathrm{Be}(10.3 \% \gamma)$ was measured with the use of a $\mathrm{NaI}$ (T1) spectrometer $7.6 \mathrm{~cm}$ in diameter and $7.6 \mathrm{~cm}$ long, which was specially designed for low-level counting (TANAKA et al., 1967). The background counting rate was $5.0 \mathrm{cpm}$ for the $477 \mathrm{keV}$ photopeak, and the counting efficiency was $14.6 \pm 0.6 \%$. The sample and the background counting runs were alternated after a period of about 1000 minutes. The decay of ${ }^{7} \mathrm{Be}$ was confirmed by remeasuring each sample 60 days after the first counting.

\section{Result AND Discussion}

Our result is tabulated in Table 1 together with the data obtained by LAL et al. (1960). In Fig.1, the production rates of ${ }^{7} \mathrm{Be}$ are plotted as a function of atmospheric depth. In the high energy region $(\geqslant 1 \mathrm{GeV})$ of the atmospheric cosmic rays, the ratio of protons to neutrons is nearly unity, while below $100 \mathrm{MeV}$ it is less than 0.03 (LAL and PETERs, 1967)., Because the threshold values of the ${ }^{7} \mathrm{Be}$ producing reactions from ${ }^{16} \mathrm{O}$ are in the range of $25-90 \mathrm{MeV}$, the observed ${ }^{7} \mathrm{Be}$ at sea level is produced mostly by neutrons.

The atmospheric neutron spectra were studied by Hess et al. (1959), YAMASHITA et al. (1966), TAJIMA et al. (1967) and others. Except those given by Hess et al. (1959), almost all spectra are for the low energy region, $\leqslant 10 \mathrm{MeV}$. The production rate of ${ }^{7} \mathrm{Be}$ from oxygen target at the sea level, $\lambda=25^{\circ} \mathrm{N}$, was calculated by means of the neutron flux and the excitation function given by BERNAS et al. (1967). In our calculation, the shape of the neutron spectrum reported by Hess et al. (1959) was used by normalizing the neutron flux at $10 \mathrm{MeV}$ to that of TAJIMA et al. (1967). The excitation function by BERNAS et al. (1967) measured for ${ }^{16} \mathrm{O}(\mathrm{p}, \mathrm{sp} .)^{7} \mathrm{Be}$ was assumed to be valid for ${ }^{16} \mathrm{O}(\mathrm{n}, \mathrm{sp} .)^{7} \mathrm{Be}$ in high energy region. The calculated value is shown in Table 1. It is in good agreement with our experimental value.

The flux of the atmospheric neutrons at depths deeper than $200 \mathrm{~g} / \mathrm{cm}^{2}$ (equilibrium region) decreases exponentially with the atmospheric depth, but the shape of spectrum remains unchanged. The production rates of ${ }^{7} \mathrm{Be}$, therefore, must decrease exponentially 
Table 1. Production rate of cosmic-ray induced ${ }^{7} \mathrm{Be}$ from Oxygen

\begin{tabular}{|c|c|c|c|c|c|c|c|}
\hline Sample & Location & $\begin{array}{c}\text { Weight } \\
\text { of target } \\
\left(\mathrm{H}_{2} \mathrm{O}, \mathrm{kg}\right)\end{array}$ & $\begin{array}{c}\text { Exposure } \\
\text { interval } \\
\text { (days) }\end{array}$ & $\begin{array}{l}\text { Chemical } \\
\text { yield } \\
(\%)\end{array}$ & $\begin{array}{l}\text { Net dpm } \\
\text { at } t=0 \\
\text { after } \\
\text { exposure } \\
\times 10^{1} \\
\end{array}$ & $\begin{array}{c}\text { Production rate } \\
\text { (experimental) } \\
\text { atoms/ } \\
\text { (g target } 0 \text { ) sec } \\
\times 10^{-6}\end{array}$ & $\begin{array}{c}\text { Production rate } \\
\text { (calculated) } \\
\text { atoms/ } \\
\text { (g target 0) sec } \\
\times 10^{-6} \\
\end{array}$ \\
\hline I & $\begin{array}{l}\text { 5th station of } \\
\text { Mt. Fuji } \\
25.5^{\circ} \mathrm{N} \\
772 \mathrm{~g} / \mathrm{cm}^{2}\end{array}$ & 390 & 99 & 91.2 & $3.02 \pm 0.51$ & $2.40 \pm 0.40$ & \\
\hline II & $\begin{array}{l}\text { Tokyo } \\
25^{\circ} \mathrm{N} \\
\text { Sea level }\end{array}$ & 1127 & 153 & 86.8 & $1.47 \pm 0.19$ & $1.47 \pm 0.07$ & 0.48 \\
\hline III & $\begin{array}{l}\text { Gif-sur-Yvette } \\
50^{\circ} \mathrm{N} \\
1030 \mathrm{~g} / \mathrm{cm}^{2}\end{array}$ & 660 & 127 & 97.8 & $2.78 \pm 0.50$ & $1.0 \pm 0.2$ & \\
\hline & $\begin{array}{l}\text { Echo Lake } \\
51^{\circ} \mathrm{N} \\
685 \mathrm{~g} / \mathrm{cm}^{2}\end{array}$ & 395 & 85 & - & - & $9.0 \pm 1.0 *$ & $9.8 * *$ \\
\hline
\end{tabular}

* LaL et al. (1960).

The branching ratio $11.0 \%$ was adopted for gamma-ray of ${ }^{7} \mathrm{Be}$.

Therefore, this value must be corrected to $(9.6 \pm 1.0) \times 10^{-6}$ atoms $/(\mathrm{g}$ target 0$) \mathrm{sec}$.

** LAL et al. (1958).

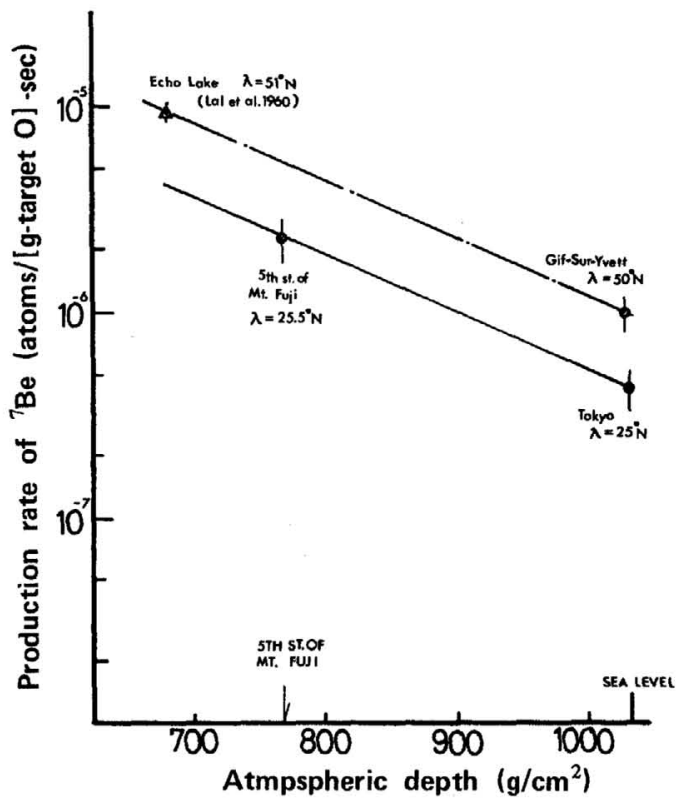

Fig.1. Production rates of ${ }^{7} \mathrm{Be}$ from oxygen as a function of atmospheric depth. The upper line corresponds to the production rates at $50^{\circ} \mathrm{N}$ and the lower one to those at $25^{\circ} \mathrm{N}$. 
with increasing atmospheric depth. Thus, the attenuation length $L$ can be calculated from our data and those of LAL et al. (1960).

$\begin{array}{llll}L & =165 \pm 30 & \mathrm{~g} / \mathrm{cm}^{2} & \text { for } \lambda=25^{\circ} \mathrm{N} \\ \text { and } & L=158 \pm 30 & \mathrm{~g} / \mathrm{cm}^{2} & \text { for } \lambda=50^{\circ} \mathrm{N}\end{array}$

Both values agree with each other and also with the presently accepted value, $L=160$ (MABUCHI et al., 1971) as the attenuation length of the atmospheric neutron.

The variation of the production rates as a function of latitude should reflect that of atmospheric neutron flux. From the comparison of the two results at sea level, Tokyo and Gif-sur-Yvette, the lattitude effect of neutrons can be obtained.

$$
\frac{\phi \mathrm{n}\left(25^{\circ} \mathrm{N}\right)}{\phi \mathrm{n}\left(50^{\circ} \mathrm{N}\right)}=0.42 \pm 0.15
$$

This value is smaller than that of 0.76 given by RosE et al. (1956) who measured it with a physical method. Similar discrepancy was mentioned earlier on the production of ${ }^{32} \mathrm{P}$ from sulfur by MABUCHI et al. (1971).

RAMA and Honda (1961b) measured ${ }^{7} \mathrm{Be}$ activities in the stratosphere and found that the measured values are only about 60 percent of the values calculated for static stratosphere. Their calculation is based on the production rate, $0.9 \times 10^{-5}$ atoms (g target $O)^{-1} \sec ^{-1}$ obtained by the exposure experiment at the Echo lake $\left(\lambda=51^{\circ} \mathrm{N}\right.$, $685 \mathrm{~g} / \mathrm{cm}^{2}$ ) by LAL et al. (1960). They ascribed this discrepancy to errors in the calculations and in the experiment. The value of $0.9 \times 10^{-5}$ atoms $(\mathrm{g} \operatorname{target} \mathrm{O})^{-1} \mathrm{sec}^{-1}$ at $\lambda=51^{\circ} \mathrm{N}$ by LAL et al. (1960), however, occupies a reasonable position in the production rate-altitude diagram in Fig.1.

\section{ACKNOWLEDGMENT}

We are grateful to Prof. S. TANAKA who kindly permitted us to use his low-level scintillation spectrometer. We are indebted to Dr. K. SAKAMOTO, Mr. K. KomURA, Mr. T. InOUE and Mr. Y. TAGUCHI of Institute for Nuclear Study, University of Tokyo for their cooperation in low-background gamma-ray countings. We also wish to express our thanks to Prof. M. HONDA and Mr. R. GENSHO of Institute for Solid State Physics, University of Tokyo for their kind advices to our discussion. A part of this study was carried out at Centre des Faibles Radioactivités, CNRS in France during MABUCHI's stay as a visiting researcher. Thanks are due to Drs. J. LABEYRIE and Y. YOKOYAMA who made this possible.

\section{REFERENCES}

Bhandari, N., Fruchter, J. and Evans, J. (1969) Rates of production of Na-24 and Mg-28 in the atmosphere by cosmic radiation. Earth Planet. Sci. Let. 7, 89-92.

Bernas, R., Gradsztajn, E., ReEves, H. and SchatzMan, E. (1967) On the nucleosynthesis of $\mathrm{Li}, \mathrm{Be}$ and B. Annals of Phys. 44, 426-478.

Hess, W. N., Patterson, H. W., WAllaCe, R. and Chupp, E. L. (1959) Cosmic-ray neutron energy spectrum. Phys. Rev. 116, 445-457. 
HUSAIN, L. and KURODA, P. K. (1968) Cosmic-ray produced radioactivity in laboratory chemicals. J. Inorg. Nucl. Chem. 30, 1121-1124.

LAL, D. and PETERS, B. (1967) Cosmic ray produced radioactivity on the Earth. Handbuch der Physik, XLVI/2, 552-612, Springer-Verlag.

LaL, D., Malhotra, P. K. and Peters, B. (1958) On the production of radioisotopes in the atmosphere by cosmic radiation and their application to meteorology. J. Atmos. Terr. Phys. $12,306-328$.

LAL, D., ARNOLD, J. R. and Honda, M. (1960) Cosmic-ray production rate of Be-7 in oxygen, P-32, P-33, S-35 in argon at mountain altitude. Phys. Rev. 118, 1626-1632.

Mabuchi, H., Gensho, R., Wada, Y. and Hamaguchi, H. (1971) Phosphorus-32 induced by atmospheric cosmic rays in laboratory chemicals. Geochem. J. 4, 105-110.

RAMA and HONDA, M. (1961a) Cosmic ray induced radioactivity in terrestrial materials. J. Geophys. Res. 66, 3533-3539.

RAMA and HONDA, M. (1961b) Natural radioactivity in the atmosphere. ibid. 66, 3227-3231.

Rose, D. C., Fenton, K. B., Katzman, J. and Simpson, J. A. (1956) Latitude effect of the cosmic ray nucleon and meson components at sea level from the arctic to the antarctic. Can. J. Phys. 34, 968-984.

TAJima, E., Adachi, M., Doke, T., Kubota, S. and Tsukuda, M. (1967) Spectrum of cosmic ray produced neutrons. J. Phys. Soc. Japan 22, 355-360.

TAKAGI, J. and TANAKA, S. (1969) Cosmic-ray muon-induced iron-59 in cobalt. J. Geophys. Res. 74, 3219-3225.

TANAKA, S., SAKAMOTO, K. and TAKAGI, J. (1967) An extremely low-level gamma-ray spectrometer. Nucl. Instr. Methods 56, 319-324.

YAmashita, M., STEPhens, L. D. and PATTERSON, H. W. (1966) Cosmic ray produced neutrons at ground level; Neutron production rate and flux distribution. J. Geophys. Res. 71, 38173834. 